\title{
Controversias sobre sistemas electorales \\ y sus efectos
}

\author{
Controversies about Electoral Systems \\ and their Effects
}

\section{Dieter Nohlen}

\section{Sumario:}

I. Duverger y las "leyes sociológicas"

II. Stein Rokkan y el sistema electoral como variable dependiente

III. Douglas W. Rae y el enfoque comparativo-cuantitativo

IV. Giovanni Sartori y el ímpetu del "electoral engineering"

V. Arend Lijphart y el afán de la precisión cuantitativa

VI. Resumen

VII. Bibliografía 


\section{Resumen}

La investigación sobre sistemas electorales y sus efectos está marcada por grandes controversias. El presente artículo tiene como objetivo reconstruir de manera lo más cercana posible al texto original y su contexto argumentativo las diferentes posturas. Estas se expresan en la articulación de los intereses cognitivos, en los enfoques y métodos de investigación, en las definiciones de los conceptos y en la relación supuestamente causal entre las variables en juego, así como finalmente en los enunciados sobre los efectos de los sistemas electorales y en las opciones entre ellos. El artículo analiza la teoría de los sistemas electorales de manera sistemática en su dimensión histórica a través de los aportes controvertidos de cinco significativos investigadores sociales, provenientes de cinco distintos países que a nivel nacional e internacional han marcado diferencias: Maurice Duverger, Stein Rokkan, Douglas W. Rae, Giovanni Sartori, y Arend Lijphart. Un sexto autor queda algo oculto, pero está obviamente presente. Es el autor mismo de estas observaciones. Su contribución a la investigación sobre sistemas electorales, que atraviesa el análisis de los transcendentes aportes de sus colegas, ha encontrado en algunas de las obras referidas también una recepción controversial.

\section{Abstract}

Research on electoral systems and their effects is subject to great controversies. This article aims to present and analyze the different positions in the debate, by reproducing the original text as closely as possible and by including the corresponding context. The presentation of each position is expressed in terms of its cognitive interests, research methods, definitions of concepts and assumed causal relationships between the involved variables, as well as a the particular statements about the effects of electoral systems and the options among them. The article systematically analyzes the theory of electoral systems from a historical perspective by assessing the controversial contributions of five important social researchers, who have made a difference at national and international levels: Maurice Duverger, Stein Rokkan, Douglas W. Rae, Giovanni Sartori, and Arend Lijphart. A sixth author, the author of these observations, is somewhat hidden but undeniably present in the discussion. His own comparative studies on electoral systems - where the analysis of the transcendental contributions of his colleagues come togetherhave also obtained a controversial acceptance in some of the referred works.

Palabras clave: sistemas electorales, sistema de partidos políticos, leyes sociológicas, representación por mayoría, representación proporcional, proporcionalidad, Duverger, Rokkan, Rae, Sartori, Lijphart, Nohlen.

Keywords: electoral systems, party systems, sociological laws, majority representation, proportional representation, proportionality, Duverger, Rokkan, Rae, Sartori, Lijphart, Nohlen. 
Las controversias sobre sistemas electorales tienen como objeto los efectos que ellos ejercen sobre los sistemas de partidos políticos. Esta definición, por su parte, ya es controversial; pues las controversias científicas al respecto se dirigen a las relaciones entre sistemas electorales y sistemas de partidos en general, suponiendo una relación de dependencia mutua entre ellos. En el centro se sitúa la cuestión de la causalidad y cómo se le puede abordar y aclarar. En contraste, las controversias políticas tematizan en primer lugar la opción entre uno u otro sistema electoral. Las respectivas fundamentaciones se deducen de diferentes consideraciones entre las que las científicas figuran generalmente como secundarias.

No obstante, también en la investigación sobre sistemas electorales se han llevado a cabo grandes controversias marcadas por diferentes apreciaciones de las ventajas y desventajas de los sistemas electorales. A menudo se cita la controversia clásica entre John Stuart Mill y Walter Bagehot que se desarrolló en el siglo XIX. Sin embargo, y visto más de cerca, la ocupación académica en sistemas electorales equivale más bien a una ininterrumpida serie de esfuerzos de corresponder mejor al reto científico del objeto de estudio. En este quehacer continuo, los autores tratan de diferenciarse, sea de forma explícita o implícita, a través de aplicar, por ejemplo, un enfoque de investigación distinto, de definir la cuestión cognitiva de forma más estrecha o más amplia, de proceder usando diferentes métodos o de vincular su abordaje metodológico con pretensiones científicas más generales o más precisas. Así, en su continuidad, las controversias científicas sobre sistemas electorales equivalen de alguna forma a una historia misma de la investigación sobre el objeto. En este sentido, representantes recientes de esta rama del saber presentan esta historia con gusto como una historia exitosa, dado que se ha pasado, como dicen, de una ciencia incipiente hacia una ciencia madura. Esta percepción no escapa tampoco de ser considerada como controversial.

En efecto, en el desarrollo de la investigación sobre sistemas electorales, no se ha preferido un estilo cooperativo-acumulativo, sino controversial-individualizante. Cada investigador cultivaba su jardín de conceptos y enunciados. Este estilo ha facilitado enormemente la crítica respecto al estado de investigación sobre sistemas electorales. Así no sorprende la respectiva crítica demoledora por parte de Arend Lijphart a mitad de los años ochenta (Lijphart, 1985), la que se podría fácilmente continuar. Concordante con este estilo se ha recordado a 
los aportes de los representantes clásicos a la investigación anterior sólo de manera esquemática, fijándose en una tesis controversial de ellos, cuyo rechazo se evidenciaba a partir de la función que tenía adscrita en la argumentación del que la citaba, hecha fuera del contexto original, del cual, sin embargo, recibía su fundamentación.

Las consideraciones siguientes tienen como objetivo, reconstruir de manera lo más cercana posible al texto original y su contexto argumentativo las posturas y controversias en la investigación sobre sistemas electorales. Se reproducirá la investigación sobre sistemas electorales en su dimensión histórica a través de los aportes de cinco investigadores sociales, provenientes de distintos países que a nivel nacional e internacional han marcado diferencias: Maurice Duverger, Stein Rokkan, Douglas W. Rae, Giovanni Sartori, y Arend Lijphart. Un sexto autor queda algo oculto, pero está obviamente presente. Es el autor mismo de estas observaciones. Su contribución a la investigación sobre sistemas electorales, que atraviesa los comentarios de los colegas, ha encontrado en algunas de las obras referidas también una recepción controversial.

\section{Duverger y las "leyes sociológicas"}

Las investigaciones de Maurice Duverger sobre los efectos de los sistemas electorales fueron las que hasta ahora tuvieron mayor resonancia a nivel mundial. Pocos tratados científicos sobre sistemas electorales pueden darse el lujo actualmente de prescindir de Duverger. Con frecuencia, el punto de contacto es, evidentemente, la crítica para diferenciarse de su teoría sobre sistemas electorales, al tiempo que se le cita sólo de forma incompleta. Por otra parte, para debatir a Duverger es necesario tomar en cuenta que su teoría es cambiante (para no decir ambigua) a lo largo de la controversia científica que ha generado. Esto transciende en la comparación de sus publicaciones (1950, 1951, 1955, 1984, 1986, entre otros) y traspasa a las traducciones a otros idiomas ${ }^{1}$ de forma que en casi cada idioma se discute un Duverger diferente, acorde con distintos textos de base francesa.

1 Su obra clásica Los partidos políticos de 1951, segunda edición 1954, fue traducida al inglés en 1954, al castellano en 1957, al alemán en 1959. 
Así, el objetivo de Duverger es presentar una teoría general sobre partidos. En relación con la formación de los sistemas de partidos, se centra en tres factores generales que en todos los países influirían en ella: factores socioeconómicos, ideológicos y técnicos. Entre estos factores Duverger presta especial atención a los factores técnicos, es decir al sistema electoral. Las razones cambian según la versión idiomática de su obra. En la edición castellana, la particular atención se entiende porque "el régimen electoral es el más importante" entre los factores generales (Duverger, 1957: 232), en la versión alemana, no se prioriza ningún factor. Como razón se declara que en relación con este factor queda "un vacío por llenar" (Duverger, 1959: 218).

Duverger persigue un enfoque comparativo empírico-cualitativo que se basa en la comprensión de que un sistema de partidos sería "el resultado de factores numerosos y complejos, unos propios a cada país y otros generales" (Duverger, 1957: 231; 1959: 217). Por tanto, intercala permanentemente el punto de vista individualizador con el generalizador. La comparación tanto diacrónica como sincrónica de una selección de países entre 1850 hasta aproximadamente 1950 lo lleva a enunciados obtenidos por inducción que, por lo general, están cimentados de forma lógica-deductiva, de tal forma que en ocasiones los dos tipos de enunciados se mezclan entre sí. En su clasificación sobre los sistemas electorales, Duverger diferencia principalmente entre sistema de mayoría relativa (o de pluralidad), sistema mayoritario con segunda vuelta y representación proporcional, haciendo, a su vez, una subclasificación del sistema proporcional también en proporcional "puro" y en aquellos sistemas que permiten una distorsión del número de escaños parlamentarios en relación con los votos obtenidos (Duverger, 1957: 322; 1959: 306). Además, toma en cuenta diversos elementos técnicos de los sistemas electorales (por ejemplo, el tamaño de la circunscripción), cuando el esquema ternario no parece funcionar. Diferencia los sistemas de partidos por su número en sistemas bipartidistas y sistemas multipartidistas o pluripartidistas.

No obstante, su gran fama se la debe Duverger a la conexión establecida por él entre los tipos de sistemas electorales que observó y las dos clases de sistemas partidos. Encuentra así una relación causal muy estrecha entre sistema de mayoría relativa y sistema bipartidista. "De todos los esquemas que hemos definido en este libro, este último es, sin duda, el más próximo a una verdadera ley sociológica" (Duverger, 1957: 245). Para explicar la relación de dependencia entre sistema de 
mayoría relativa y sistema bipartidista, Duverger hace referencia a dos factores elementales que inciden: el factor mecánico y el factor sicológico. Desde entonces, la doctrina sobre sistemas electorales diferencia así estos factores: el primero expresa la desventaja no proporcional que tiene un tercer partido más débil en la distribución de escaños en un sistema de mayoría relativa. El segundo expresa el recelo del elector a votar por un partido que no tiene posibilidades de alcanzar una representación parlamentaria, es decir, el temor de que su voto no cuente (ibidem: 252). Duverger relaciona los dos tipos básicos adicionales de sistemas electorales con el sistema multipartidista. En la formulación más divulgada, las tres fórmulas que se han integrado como "leyes de Duverger" al estudio de los sistemas electorales, son las siguientes:

(1) La representación proporcional tiende a un sistema de partidos múltiples, independientes y estables (con excepción de los movimientos que surgen repentinamente). (2) El sistema mayoritario con dos vueltas, tiende a un sistema multipartidista, con partidos elásticos, dependientes y relativamente estables (en todos los casos). (3) El sistema de mayoría relativa (con una sola vuelta) tiende a un sistema dualista con partidos grandes e independientes, que se alternan entre sí. Sin embargo, estos enunciados muy generales solamente demuestran tendencias básicas... (1950: 13). ${ }^{2}$

Es bien sabido que las tres "leyes" provocaron enormes controversias científicas, sobre todo a raíz de que los críticos de Duverger quisieron endosarle más de lo que evidentemente quiso expresar, tal como sugiere la frase que viene justamente después de sus fórmulas.

¿Qué quieren decir las tres "leyes"? Duverger intenta, en tres ocasiones, recoger en palabras la conexión entre sistema electoral y sistema de partidos. Él mismo confiesa que determinados errores de interpretación han resultado debido a sus propias formulaciones tentativas e imprecisas. Reconoce en primer lugar pasar de términos más estrictos (sociological laws) a unos menos determinantes (fórmulas) para reafirmar finalmente su definición inicial (Duverger, 1986: 70). Reconoce en segundo lugar haber variado en el tiempo la relación causa-efecto

2 En la versión original francesa: el sistema proporcional "tend à un système de partis multiples, rigides et independants les uns des autres”, el sistema de mayoría absoluta "tend à un système de partis multiples, souples et dépendants les uns des autres", el sistema de mayoría relativa "tend au dualisme des partis" (Duverger, 1950: 7). 
entre sistemas electorales y sistemas de partidos en el sentido de recalcar su carácter de tendencia al sustituir un "conduce hacia" (leads to) por "tiende a conducir hacia" (tends to lead). Así, Duverger confirma en los años ochenta (Duverger, 1986: 170) finalmente la formulación de sus "leyes sociológicas" definidas en 1955: "(1) El sistema proporcional tiende a conducir a la formación de muchos partidos independientes... (2) El sistema mayoritario tiende a la formación de muchos partidos que se coaligan entre ellos...(3) el sistema de mayoría relativa tiende a producir un sistema bipartidista" (Duverger, 1955: 113). ${ }^{3}$ Hace entender que las leyes sólo expresan "tendencias básicas que interactúan con factores nacionales y sociales". Pero no olvida añadir que "en las últimas ediciones de sus obras, en la segunda ley se sustituyó 'tiende' por 'tiende a producir"' (idem). De paso, cambia el orden de las "leyes" (véanse Duverger, 1984: 35, y 1986: 70).

En la traducción de su principal obra al inglés, en relación con la primera "ley", se traduce "tend" por "favours" (Duverger, 1954: 217), en la versión española se traduce literalmente "tend" por "tiende" (Duverger, 1957: 232), así como también en la versión alemana, donde se traduce "tend" por "conduce hacia" (führt zu) (Duverger, 1959: 219). Esta última versión de las "leyes" es especialmente desconcertante porque incita a deducir por ejemplo que la representación proporcional tiene como efecto el aumento del número de partidos (multiplication). Sin embargo, Duverger solamente quiere decir que la representación proporcional va de la mano del sistema multipartidista (multipartism), que éste conserva el número de partidos que existían en el momento de su introducción (Duverger, 1986: 71). Así, las traducciones citadas que pierden el importante detalle del autor de las "leyes sociológicas" de haber sustituido "leads" por "tends to lead", completan la imprecisión del propio Duverger y de la controversia sobre su obra. Al final, Duverger mismo se adelanta al enorme margen de maniobra interpretativo de sus fórmulas, llevándolo desde una relación cuasi causal hasta una interrelación de múltiples causas y efectos. Como sus críticos lo perciben principalmente como un representante de rígidas "leyes sociológicas", puede por fin presentarse casi como testigo principal en

Traducido del inglés: (1) Proportional representation tends to lead to a system of many mutually independent parties,...(2) the two ballot majority system tends to lead to a multipartism moderated by alliances of many parties(3) the plurality method tends to lead to a two-party system" (Duverger 1984: 35). 
contra de la "errada interpretación" (Duverger, 1986: 69 y ss.) de sus observaciones.

¿En las tres fórmulas se agotan los efectos que tienen los sistemas electorales sobre el sistema de partidos? ¡Evidentemente que no! En su obra clásica, el propio Duverger varias veces lo observa de forma inequívoca: las tres fórmulas "de ninguna manera abarcan todas las influencias de la mecánica electoral sobre el régimen de partidos" (Duverger, 1959: 219).

¿En el sistema electoral se agotan los factores que influyen sobre el sistema de partidos? Duverger constata de forma casi apodíctica: "La relevancia del sistema electoral tiene sus límites" (Duverger, 1959: 308; 1957: 324). Está muy lejos de rendir tributo a la causa, con un monocausalismo. Al ponderar el peso de diversos factores, él niega que la influencia del sistema electoral "sea mayor al de otros factores". Más bien subraya: “... el sistema electoral nunca (es) el verdadero motivo, más bien son las especificidades nacionales, las ideologías, pero sobre todo la estructura de la sociedad económica, la que influye decisivamente" (Duverger, 1959: 219). Con razón anota: "Pero no por ello se debe menospreciar la importancia de un factor general puramente técnico, como el sistema electoral" (Duverger, 1959: 232; 1957: 245).

¿Se agota la conexión entre sistema electoral y sistema de partidos en una relación unilateral? Muchos de los críticos de Duverger cuestionan la orientación de causalidad de sus fórmulas, como lo hace por ejemplo Leslie Lipson en su análisis del sistema bipartidista británico, retrocediendo hasta muy atrás en la historia, es decir, revisando justamente el caso paradigmático de la conexión entre sistema de mayoría relativa y sistema bipartidista (Lipson, 1953). Sin embargo, el propio Duverger reflexiona: "Al contrario, el sistema de partidos por su parte también ejerce una gran influencia sobre la técnica electoral, cuando (por ejemplo) el sistema bipartidista favorece el sistema de mayoría relativa" (Duverger, 1959: 218), "desempeña un papel capital" en el sistema electoral (Duverger, 1957: 232). Llega a la decisiva conclusión: "En resumen, el sistema de partidos y el sistema electoral están íntimamente ligados y a veces también es difícil diferenciarlos al momento de analizar su efecto" (Duverger, 1959: 219; 1957: 232).

¿Cómo entendería Duverger sus fórmulas: como deterministas o como probabilistas? Incluso relativiza, al hacer referencia a la que, según él, es la fórmula que más se acerca a una "ley sociológica": "El sistema de mayoría relativa empuja al dualismo, pero no conduce a 
él necesaria y obligatoriamente y en contra de todos los obstáculos" (Duverger, 1959: 242, 1957 255). En sus fórmulas se habla "por supuesto sólo de tendencias generales, a las que a menudo se le atraviesan otros factores..." (Duverger, 1959: 306; 1957: 322). En la obra de Duverger existen suficientes indicios para pensar en una comprensión solamente probabilística de sus fórmulas. No obstante, éstas fueron interpretadas por sus numerosos críticos como deterministas. Al parecer, este malentendido parece haber agradado a Duverger durante mucho tiempo. En una misma disertación de 1984 cita sus opiniones una vez como Duverger's law (Duverger, 1984: 36), otra vez explica: "Leyes sociológicas que también se pueden considerar como hipótesis de trabajo" (ibidem: 39). Dos años más tarde aclara (¿indudablemente?): "Las proposiciones concernientes al multipartidismo bipolar no son ni leyes sociales ni hipótesis: solo son indicios basados en algunas observaciones con el fin de justificar conclusiones bien fundadas" (Duverger, 1986: 84) Duverger juega en mayor o menor medida con este concepto de ley, a ratos lo usa, otros lo reemplaza, a ratos lo interpreta usando términos menos deterministas como tendencia, esquema, fórmula, modelo, hipótesis, sugerencia — confundiendo con su ambigüedad mucho a un público que igualmente está acostumbrado a usar diferentes conceptos de "ley"-. Sin lugar a dudas, sus sociological laws son para el mismo Duverger más que solamente un estímulo, le sirven de modelo de interpretación de la realidad. Da por entender que la evolución del sistema de partidos de la República de Bonn de aquella época - encaminada hacia un sistema de dos partidos y medio y contradictoria a las experiencias usuales obtenidas con sistemas de representación proporcional- se debe a la "naturaleza mixta" del sistema electoral, concretamente a la influencia del primer voto unipersonal de mayoría relativa sobre el segundo voto proporcional de lista en el sistema de dos votos. Define el sistema electoral alemán de manera que le permite salvar su teoría. Supone que este sistema electoral "contribuye a promover los efectos del dualismo del sistema de mayoría relativa en distritos unipersonales sobre el segundo voto que es contabilizado según la representación proporcional" (Duverger, 1984: 37). Su teoría de sistemas electorales también se expresa en su opción y recomendación. "El sistema de pluralidad y el de doble vuelta son ciertamente preferibles a la representación proporcional en todos los sistemas en los cuales la investidura y mantenimiento del gobierno depende de la mayoría legislativa" (idem). "Debe quedar claro que la 
representación proporcional generalmente debilita el sistema democrático y el sistema de mayoría lo fortalece" (ibidem: 35 ).

Después de Duverger, se plantea la pregunta que posteriormente también retomará Giovanni Sartori (1994: 40): “¿Pueden los efectos del sistema electoral ser formulados en forma de una ley?”. Hubo fuerte oposición a esta posibilidad. Vernon Bogdanor resume la negación casi generalizada con la siguiente frase: "Las relaciones entre el sistema electoral, sistema de partidos y el proceso de cambio social son recíprocas y de alta complejidad. No son del tipo que se puedan asumir como leyes científicas, sean esas leyes aritméticas, institucionales o sociológicas" (Bogdanor, 1983: 261). Sartori, en cambio, hace el cuestionable intento de formular las "leyes sociológicas" de Duverger de tal forma que puedan aplicarse como leyes. Haré referencia a este punto posteriormente cuando presente la postura científica de Sartori.

No cabe duda que Duverger es un clásico. Lo es en el sentido de que un clásico provoca diferentes interpretaciones, debido a veces a contradicciones internas así como a un uso oscilante del idioma. Considerando el intervalo temporal, lo es también por haber precisado cuestiones de investigación más que resultados seguros (véase Häberle, 1981). Y finalmente, por haber motivado un sinnúmero de estudios, en defensa así como en rechazo de sus enunciados, y por haber producido también un contra-clásico que le ha duramente criticado y al mismo tiempo proseguido. Para la "ciencia política normal" (Kuhn, 1971), sin embargo, se ganaría mucho si las fórmulas de Duverger no fueran entendidas como leyes que deban refutarse o reformularse por enésima vez, sino si se pueden comprender de forma heurística en el sentido planteado por Max Weber (1956: 234 y ss.), como relaciones de tipo ideal para preguntarse a continuación, a partir de qué factores prevalecen las discrepancias observables en la realidad.

\section{Stein Rokkan y el sistema electoral como variable dependiente}

El interés cognitivo primordial de Stein Rokkan gira en torno a las diferencias centrales en la estructura del sistema de partidos en los países de Europa occidental (cfr. Flora, 1981: 428). "Sintetizando estrategias de análisis diacrónico y sincrónico” (Lipset y Rokkan, 1967: 54) su enfo- 
que es de naturaleza histórico-genética. Su material histórico abarca el periodo desde inicios de la representación parlamentaria en el siglo XIX hasta los años sesenta del siglo pasado, en realidad solamente hasta los años veinte, pues afirma que para el tiempo posterior a éstos se habría producido un congelamiento de los sistemas de partidos: "El sistema de partidos de los 1960's refleja, con pocas pero importantes excepciones, el clivaje de estructuras de los años 1920" (ibidem: 50).

El modelo de base para la explicación de la evolución de los sistemas de partidos son las líneas de conflicto históricas al interior de una sociedad que son trasladadas a sistemas nacionales de partidos, dentro del contexto de la superación secuencial de diversos retos. Rokkan diferencia entre cuatro retos o umbrales de este tipo que surgieron en los procesos de democratización de todos los países de Europa occidental: legitimidad (reconocer como legítima la crítica y protesta en contra de los que ejercen el poder), incorporación política (derechos de participación y libertad), representación (representación proporcional parlamentaria) y la asunción del poder (influencia sobre las decisiones del Ejecutivo), dando gran relevancia a la secuencia temporal, en la que se superan los umbrales, como razón para las diferencias en el desarrollo de los sistemas de partidos en Europa occidental (Rokkan, 2000: 296 y ss.).

En realidad, Rokkan solamente se interesa por cuestiones relativas a los sistemas electorales, dentro del contexto de este proceso de democratización. Presta poca atención a Maurice Duverger, aunque sí acepta que "en términos teóricos abstractos se podría, sin lugar a dudas, plantear la hipótesis que un sistema de mayoría relativa en regiones culturalmente homogéneas... más bien podría conducir a sistemas bipartidistas y que solamente se sumarían otros partidos si aparecen clivajes" (ibidem: 360). Naturalmente caldea así la controversia sobre los sistemas electorales, de manera que desarrolla la relación de efecto clásica entre la variable considerada como independiente y la considerada como dependiente, específicamente entre sistema electoral y sistema de partidos, haciendo de ellas un set de variables que van a depender de una tercera variable, las estructuras sociales de las líneas de conflicto. Por lo demás, Rokkan rompe con la orientación hacia el efecto que existía hasta esa fecha, en cuanto a la supuesta relación de causalidad entre sistema electoral y sistema de partidos: "De hecho, en la mayoría de los casos es poco significativo tratar el sistema electoral como variable independiente y el sistema de partidos como depen- 
diente. Las estrategias partidarias tienen, generalmente, influencia decisiva en la legislación electoral..." (Lipset y Rokkan, 1967: 30). Sobre la base de sus investigaciones históricas-genéticas, Rokkan llega a la conclusión que el sistema electoral depende del sistema de partidos, de su estructura como reacción a las evoluciones políticas que se producen a partir de la dinámica de las estructuras predominantes en las líneas de conflicto. En el marco de su teoría sobre umbrales, los sistemas electorales adquieren relevancia en tanto contienen diversas barreras para la representación. Por tanto, reconoce que la introducción de la representación proporcional es un resultado histórico de la "convergencia de las presiones desde arriba y desde abajo. La clase obrera en ascenso quería bajar la barrera de representación para obtener el acceso a la legislatura, y los partidos establecidos considerando su mayoría en peligro demandaban la representación proporcional para proteger su posición frente a las nuevas olas de movilización de electores bajo el voto universal" (ibidem: 32; véase también Rokkan, 2000: 363). En este punto, la diferencia que hace Sartori entre sistemas electorales "débiles" y "fuertes" le va muy bien (al respecto, véase más adelante), en tanto que "la opción por un sistema electoral proporcional se podría caracterizar como la estrategia de los débiles" (Rokkan, 2000: 312) que él habría encontrado especialmente en países más pequeños. En general, habría observado lo siguiente: mientras mayor la heterogeneidad étnica y/o religiosa en una sociedad, tanto más el legislador se decide a favor de un sistema proporcional: "En sociedades divididas por el idioma y la religión, la representación según el principio mayoritario podría poner claramente en peligro la subsistencia del sistema político" (ibidem: 363).

La importancia central que Rokkan atribuye a éste y otros factores sociales en la evolución del sistema de partidos, ${ }^{4}$ lo coloca en una controversia con teóricos como Giovanni Sartori que tienen grandes expectativas con respecto a los sistemas electorales y las reformas de los sistemas electorales: "Ellos querían influir en el curso de los eventos futuros y tendían a ser exageradamente optimistas sobre las posibilidades de provocar cambios en el sistema de partidos establecido mediante la ingeniería electoral" (Lipset y Rokkan, 1967: 30). Rokkan considera que no sólo los sistemas de partidos, sino también las re-

$4 \mathrm{Al}$ respecto, véase la reconstrucción de la teoría de Rokkan por parte de Peter Flora en Rokkan (2000). 
glas de juego institucionales estarían "congelados". Pero enfrenta la crítica, en el sentido de que justamente por su perspectiva históricogenética, su teoría sobre los sistemas de partidos estaría estrechamente vinculada con la respectiva época y que no podría aplicarse a evoluciones posteriores (Lipset, 1985; Pappi, 1989). No obstante, su postura de que los sistemas electorales puedan ser considerados también como una variable dependiente del correspondiente contexto histórico puede considerarse como un postulado independiente de condiciones espacio-temporales.

\section{Douglas W. Rae y el enfoque comparativo-cuantitativo}

Para la corriente empírico-cuantitativa en el estudio de los sistemas electorales, el análisis científico de la relación causal entre sistema electoral y sistema de partidos empieza recién con Douglas W. Rae. En su obra clásica The Political Consecuences of Electoral Laws, el autor marca críticamente la diferencia con respecto a estudios anteriores, en el convencimiento de que recién su enfoque empírico-estadístico orientaría los estudios sobre sistemas electorales en la dirección correcta. ${ }^{5}$ Rae considera que hasta entonces solamente habría existido un "conocimiento convencional... más o menos inocente frente a un conocimiento general preciso" ("conventional wisdom... more or less innocent of precise general knowledge") no habría "un cuerpo de conocimiento sistemático y empíricamente fundado" ("no systematic and empirically verified body of knowledge") sobre los efectos políticos de los sistemas electorales (1967: 6; 1977: 6). Sus investigaciones, en cambio, se fundamentarían en la sistematización y en teorías generales falsa-

\footnotetext{
5 Vale señalar que Rae identifica "electoral law”(ley electoral) con "electoral system" (sistema electoral), dado que las propiedades de los "electoral laws" las define por "formas de votación, circunscripciones y fórmulas de transferir votos en escaños". Esto permite traducir "electoral law" por "sistema electoral" y sugiere evitar una traducción literal, en forma de "derecho electoral" (como aparece en la versión castellana, Rae, 1977), concepto mucho más amplio. Tal traducción peca de la misma imprecisión en la investigación sobre sistemas electorales que Rae quiere superar. En lo que sigue, se traduce de la edición original inglesa de 1967 y se indica además el lugar de las citas en la versión castellana de 1977.
} 
cionables. Estos vehementes anuncios deben cuestionarse acto seguido: por un lado, Rae naturalmente parte del análisis de los sistemas electorales realizados hasta esa fecha, especialmente por Duverger, cuyos resultados trata de ratificar empíricamente. ${ }^{6}$ Por otra parte, su enfoque apunta hacia correlaciones estadísticas que no necesariamente auguran una causalidad. Finalmente, su interés intelectual se dirige solamente hacia los efectos en los sistemas electorales y no al respectivo contexto histórico que influye en la relación entre sistema electoral y sistema de partidos. Al concluir sus investigaciones confiesa honestamente tener consciencia de estas dos limitaciones: "El presente estudio se ocupa en gran parte de problemas de correlación y no cronológicos" (1967: 146; 1977: 152). Por lo tanto, el pensamiento de Rae debe entenderse como un primer escrito relevante de un enfoque específico de análisis de los sistemas electorales (cfr. Lijphart, 1980: 483 y ss).

Este enfoque comparativo-cuantitativo se centra primero en recoger un sinnúmero de datos empíricos, lo más variado posible en lo geográfico como en lo histórico - Rae estudia las elecciones generales de 20 democracias occidentales, en el periodo comprendido entre 1945 y 1965-. En segundo lugar, se plantea una gran cantidad de hipótesis falsacionables que contienen enunciados sobre las relaciones entre las variables estudiadas y que pueden ser comprobadas, a partir del material recogido. En tercera instancia, pretende precisar exactamente el instrumental analítico del estudio y diferenciar claramente en lo operativo, tanto lo que tiene que ver con los sistemas electorales como con los sistemas de partidos. Rae subdivide los efectos de los sistemas electorales, a partir de tres de sus dimensiones: la división de un país en circunscripciones electorales (districting), la forma de emitir el voto (balloting) y el procedimiento (electoral formula), según el cual se convierten los votos en escaños. El autor estudia los efectos que tiene cada uno de estos tres elementos sobre el sistema de partidos (Rae, 1967: 6 y 16, 1977: 6 y 16). La variable dependiente "sistema de partidos" la subclasifica en el grado de proporcionalidad de los resultados electorales que presentan los sistemas electorales en el momento de convertir votos en escaños y que él define como un efecto directo del sistema electoral (proximal effect), así como en el número de partidos dentro de un sistema multipartidista, un resultado que él denomina el

6 Rae cita a Duverger (1954:217) de la siguiente manera: “The simple majority (plurality) single-ballot system favors the two-party system” (Rae, 1967: 92, 1977: 96). 
efecto distante (distal effect). Rae tiene otra categoría muy orientadora: diferencia entre las mayorías parlamentarias absolutas que se deben al voto de los electores (earned majorities) y aquellas, construidas por el sistema electoral (manufactured majorities) (1967: 74; 1977: 76). En cuanto al sistema de partidos, no observa solamente el número de partidos en el parlamento (parliamentary party system), sino también la competencia entre los partidos a nivel del electorado (elective party system) (1967: 48; 1977: 48). Estas puntualizaciones persiguen el fin de hacer operativo el objeto estudiado en lo cuantitativo, lo que, en su aplicación concreta, naturalmente no siempre conduce a resultados satisfactorios en lo cualitativo. Un terrible ejemplo de lo dicho es la equivocada valoración hecha por Rae del sistema electoral alemán, al considerarlo "half Anglo-American" “... ya que permite la elección de la mitad del parlamento federal con mayoría relativa en distritos uninominales con el simple voto personal" (1967: 45; 1977: 45). El autor entiende el sistema alemán como un sistema segmentado, lo clasifica como sistema mixto (mixed system) y en sus cálculos lo incluye en la categoría 2 por tamaño de circunscripción —algo en sí absurdo (1967: 42; 1977: 42)—, como resultado de la suma del tamaño de las circunscripciones uninominales y de la única circunscripción nacional, en la que se distribuyen todos los escaños de forma proporcional en el ámbito federal.

En lo referente a los resultados del análisis de Rae, en general se confirman los hallazgos del estudio empírico-histórico de los sistemas electorales, realizado con anterioridad a Rae y criticado por este mismo, tal como evidencia la siguiente afirmación: "Prácticamente todos los sistemas electorales producen desventajas para los partidos débiles" (1967: 88, 1977: 92). Es obvio que sobre la base de su limitado interés cognitivo y a través del método seleccionado, este autor puede hacer afirmaciones con mejor comprobación cuantitativa. Según él, la conexión entre sistema de mayoría relativa y sistema bipartidista sería más débil de lo enunciado en la "ley sociológica" de Duverger, pero sí existiría una asociación fuerte, pues coincidiría en el $89.7 \%$ de los casos (1977: 94; 1977: 97). En el resumen de sus datos también afirma lo que de todas formas debía suponerse: "La gran parte de mayorías parlamentarias de un solo partido son fabricadas por el sistema electoral" (1967: 74; 1977: 76). Además, formula condiciones secundarias que evidentemente no son sólo de naturaleza empírica, sino también lógica: "El sistema de mayoría relativa está siempre asociado a la com- 
petencia entre dos partidos, excepto cuando existen partidos locales fuertes" (1967: 95; 1977: 100). Cabe recalcar que Rae no pierde de vista los casos contrarios: "El sistema de mayoría relativa no fue por completo condición suficiente para una competencia bipartidista en Canadá y no es condición necesaria para la competencia bipartidista en Austria" (1967: 94 y ss.; 1977: 98 y ss.). De esta manera cumple con las condiciones exigidas para la aplicación exitosa del método comparativo en el diseño cualitativo.

Sin embargo, algunos resultados se caracterizan justamente por el enfoque cuantitativo del análisis, como la diferenciación de los sistemas electorales a partir del parámetro "grado de proporcionalidad de los resultados electorales", una diferenciación que se transmite sobre la base del modelo del continuo unipolar:

La principal diferencia entre los sistemas electorales se refleja en un continuo entre la proporcionalidad perfecta (en la que no ocurre una redistribución) y un extremo de desproporcionalidad (donde los partidos fuertes se benefician y los pequeños quedan en desventaja). Puesto que el extremo de perfecta proporcionalidad no es realizable, los sistemas electorales se diferencian en el grado en que difieren de ese punto hasta el extremo de ventajas considerables para los partidos fuertes (1967: 137 y ss.; 1977: 143 y ss.).

Con esta diferenciación, que condujo a Richard Rose a plantear la atrevida tesis de que las "diferencias entre los sistemas electorales" serían esencialmente "cuestión de grado y no de naturaleza" (Rose, 1984: 73), Rae subraya por una parte que habrá que definir los sistemas electorales en general a partir de sus efectos; en principio, yo concuerdo con esto. Por otra parte relativiza la influencia de los sistemas electorales, pues la limita al grado de proporcionalidad. Su influencia sería mesurable solamente dentro del ámbito de los "efectos próximos", en el ámbito de los "efectos distantes" no lo sería o no sería exactamente determinable el nivel real de esta influencia. De acuerdo con esto, el estudio empírico-estadístico solamente alcanzaría resultados relativamente precisos dentro de un campo limitado del objeto a ser investigado.

Es significativo que en la recepción científica de Rae, históricamente sólo se tomó en cuenta aquella parte de su exposición, en la que se describe la estrecha correlación (o asociación) existente entre siste- 
mas electorales y sistema de partidos, limitándolo siempre al grado de proporcionalidad de los resultados electorales, tal como se mencionara anteriormente. Pero no progresó el cuestionamiento fundamental de la correlación como tal, planteado por Rae (1967: 146; 1977: 152). Pues él mismo recalca: "La influencia de los sistemas electorales sobre sistema de partidos a nivel parlamentario es generalmente menos importante que muchas otras fuerzas que se expresan en los resultados electorales" (1967: 96; 1977: 100). También está consciente de que su análisis solamente es un recorte de un todo: "Los sistemas de partidos están influenciados por una serie de variables: sociales, económicas, legales y políticas. El efecto próximo [proximal effect] del sistema electoral sobre la representación parlamentaria de los partidos es solo uno de los varios factores determinantes" (1967: 141; 1977: 147). Retomando las dudas sobre la linealidad de la relación causa-efecto, planteada ya anteriormente por Duverger, Rae incluso las formula de la siguiente manera: "Peor aún, los sistemas electorales están ellos mismos configurados por el sistema de partidos" (idem). Diversas reservas de igual tenor ante un análisis de la relación causa-efecto también se recogen en otros puntos de su obra. Al igual que en el caso de Maurice Duverger, la referencia de los estudiosos de los sistemas electorales se centra sobre todo en aquellos pasajes de su obra que le resultan útiles, ya sea con intenciones de confirmación o de abrir controversia.

\section{Giovanni Sartori y el ímpetu del "electoral engineering"}

Entre los estudiosos de los sistemas electorales en todo el mundo probablemente Giovanni Sartori es quien alimentó con mayor impacto la controversia científica. Su interés intelectual se centra, en primera instancia, en el sistema de partidos: su estructura y dinámica. En segunda instancia, está orientado hacia el sistema electoral, pues reconoce en él el instrumento, con el cual más fácilmente se puede ejercer influencia sobre el sistema de partidos y su evolución. Percibió las posibilidades diseñadoras (en inglés: "manipulative") que ofrecen los sistemas electorales; por lo tanto, su interés se centra en la "ingeniería electoral". Sartori persigue un enfoque cualitativo-comparativo, con el que pretende llegar a reglas generales. Hace uso del procedimiento de la cla- 
sificación y dentro de éste otorga especial valor a la univocación terminológica, en crítica directa a Maurice Duverger (Sartori, 1994: IX).

Si revisamos el instrumental analítico de Sartori vemos que, con relación al sistema de partidos, el autor apuesta por la tipología (una variante de la clasificación) que se basa en varios criterios, en vez de la clasificación pura que se fundamenta en un solo criterio (Sartori, 1976: 125): a parte del número de partidos (formato del sistema de partidos) aparecen además su mecánica y dinámica, y adicionalmente el componente ideológico visto como distancia ideológica entre los partidos y su intensidad (grado de polarización). Sartori subdivide los sistemas electorales de acuerdo a dos criterios concebidos de forma dualista: primero, mayoría versus proporcionalidad, es decir: "Si la conversión de votos en escaños es en proporción”; segundo, si hay un ganador por circunscripción o dos o más ganadores (Sartori, 1994: 3). Con esto retoma la diferenciación resaltada por mí, es decir, entre el principio de representación y la regla decisoria (Nohlen, 1969: 32 y ss.; Nohlen, 1984: 83-90), así como aboga también por la clasificación de los sistemas electorales según un solo criterio, a fin de lograr la contraposición simétrica de los tipos básicos del sistema electoral. A diferencia de lo que yo planteo, Sartori toma como criterio fundamental la regla decisoria, tal como se desprende de su definición de sistema mayoritario y sistema proporcional, a la que suma además el tamaño de la circunscripción:

Un sistema electoral es mayoritario, si la votación tiene lugar en circunscripciones (por lo general, uninominales) donde el ganador se lo lleva todo o también conocido como sistema de mayoría relativa (first-pastthe-post). Por el contrario, cualquier sistema electoral en el que la votación se produce sobre la base de dos o más ganadores elegidos mediante los 'votos más altos', se trata de un sistema proporcional (Sartori 1994: 4).

Esta contraposición conceptual revive una controversia que fácilmente puede conducir a malentendidos. Al enfocar la cuestión de definición en los elementos técnicos, como lo hace Sartori, el autor puede afirmar la existencia de los denominados sistemas mixtos (mixed systems) e incluso especificarlos: "Los verdaderos sistemas mixtos son solo aquellos en los que se elige... al combinar criterios proporcionales y de pluralidad" (ibidem: 5). Mi definición básica de representación por mayoría y representación proporcional como principios de repre- 
sentación excluye los sistemas mixtos, pues los principios no se pueden mezclar. Sin embargo, no dudo en lo absoluto que en el nivel de los sistemas electorales concretos existan tipos (en mi terminología) "combinados" de sistema electoral compuestos de elementos técnicos diversos, a ratos incluso opuestos al principio de representación al que está orientado como sistema. Como extraordinario ejemplo se puede citar al sistema de representación proporcional en circunscripciones pequeñas que cuenta como sistema de mayoría. Aquí se ha integrado la regla decisoria de la proporcionalidad a un sistema electoral, cuya orientación y efecto es la representación por mayoría. En este sentido, los tipos de sistema combinado concuerdan (en mayor o menor medida) ya sea con uno de los principios de representación, o con el otro. Por lo tanto, es necesario diferenciar y se puede reconocer que la controversia entre Sartori y yo sobre los sistemas electorales mixtos se resuelve fácilmente, mientras no sucede lo mismo con la aplicación concreta de las categorías. Sartori declaró (hacia mediados de los años 1990's) que "Rusia, Italia, probablemente Japón y Nueva Zelanda” tendrían sistemas mixtos (ibidem: 12). Con eso cayó en un grave vicio de diferenciación, pues para aquel tiempo Rusia tenía un sistema segmentado e Italia un sistema compensatorio; Nueva Zelanda sigue utilizando, invariadamente, un sistema proporcional personalizado (véase Nohlen, 2009: 199 y ss.). Justamente cuando en el concepto se apunta hacia los elementos técnicos hay que diferenciar claramente entre sus combinaciones y tomar en cuenta los diversos efectos que éstos provocan.

Si diferenciamos entre objetivo versus medios, Sartori pone, por tanto, los medios en el centro de su atención y no el objetivo, coincidiendo justamente con su idea de que los sistemas electorales serían el medio más adecuado para poder influenciar el desarrollo del sistema de partidos. Tomando como máxima el pensamiento de la ingeniería electoral, el autor también hace una diferenciación en los sistemas electorales, según los efectos que ejercen los elementos técnicos sobre el grado de desproporción entre votos y escaños. Para ello utiliza el continuo unipolar de Rae que tiene su punto cero en el sistema proporcional puro, así como el sistema de valoración básica de "fuerte" y "débil". Como la representación proporcional pura refleja con mayor exactitud la correlación de la votación en el momento de la distribución de escaños, Sartori lo considera un sistema electoral débil (feeble system), incluso hasta un sistema sin efectos (no-effect-system). Los siste- 
mas electorales que se distancian del punto cero se miden por el desvío que logran provocar, partiendo del sistema proporcional: los sistemas electorales indiscutidamente fuertes (strong systems) son los sistemas de mayoría.

Dentro de esta clasificación entre sistemas electorales se evidencian ahora las estrecheces de carácter histórico-analítico que resultan de la selección de las reglas decisorias como características de definición de los sistemas electorales. Concebidos como principios de representación que se contraponen en un modelo de continuo bipolar, los sistemas electorales pueden perseguir diferentes objetivos de representación y a veces son demasiado débiles o demasiado fuertes, dependiendo del caso, para alcanzar estos objetivos. Históricamente, los sistemas de representación proporcional han sido establecidos para que el principio de la igualdad del sufragio pueda abrirse paso, en el sentido de que los votos tengan igual valor sobre el resultado. Esta es la fortaleza de los sistemas electorales proporcionales $-\mathrm{y}$ a veces también se les evalúa por ello, por ejemplo en la jurisprudencia del Tribunal Constitucional Federal de Alemania (Bundesverfassungsgericht), mientras los sistemas de mayoría resultan débiles-.

La controversia de mayor alcance de Sartori se produjo con Maurice Duverger, en torno a sus "leyes sociológicas".7 Su crítica no gira tanto en torno al intento de formular, en formato de ley, el efecto que podían tener los sistemas electorales. Es más bien la sorpresiva debilidad de Duverger al ejecutar la idea, lo que Sartori reclama: "La debilidad de tratamiento de Duverger sigue llamando la atención... La debilidad metodológica y sustantiva de las leyes de Duverger está patentada y demostrada fácilmente" (Sartori, 1986: 44 y ss.). Sartori explica en detalle:

En primer lugar... nunca da la impresión de percibir la diferencia entre "causa" y "asociado con". En segundo lugar... una ley (generalización causal) es verificable si, y sólo si, la causa y el efecto están claramente especificados, mientras que el efecto de la primera ley de Duverger (dualismo de partidos) es tan confuso como puede ser, y el efecto de su segunda ley (multipartidismo) también adolece de excesiva imprecisión (ibidem: 44).

7 Para Sartori, las "leyes sociológicas" de Duverger tienen que leerse así: (1) The ballot majority (plurality) single ballot system tends to party dualism. (2) The second ballot (majority) system and the proportional representation tend to multipartyism" (Sartori, 1986: 43 y ss.). 
En la obra de Duverger no quedaría claro, si sus mecanismos son deterministas o probabilistas (ibidem: 46). Por una parte, el texto prometería ser determinista al hablar de una ley sociológica pero, por la otra, debía tomarse en cuenta una serie de excepciones, una limitación que degradaría el enunciado a ser probabilista. En cambio, Sartori considera que sí es posible tener leyes deterministas en relación con el efecto de los sistemas electorales sobre el número de partidos, y esto, en vista de "todos y cada uno de los eventos electorales" (ibidem: 52). En similar forma también se declara opuesto a la expresión más suave al decir que existe una correlación o asociación entre sistemas electorales y sistema de partidos. Toda vez que una ley sociológica no podría ser comprobable con la ayuda de una correlación, tal como habría intentado hacer Rae con Duverger, cuando el primero comentaba que la conexión entre "sistema de mayoría relativa" y "sistema bipartidista" sería más débil de lo que se presumiría de una "ley sociológica”, pero que sí representaría una asociación fuerte, si coincidiera en el 89.7\% de los casos (idem). En suma, la versión cuantitativo-matemática de Duverger por parte de la escuela empírico-estadística no aportaría mucho. Algo de más o algo de menos - una frequency law - incluso sería contraproducente, pues "empobrece fuertemente, entre otras cosas, la información que mi enfoque a su vez aporta” (ibidem: 48).

En referencia a Duverger, Sartori intenta, en cambio, expresar con mayor precisión las "leyes sociológicas" de éste y formularlas a través de condiciones adicionales, de tal forma que aquellos casos que hasta ese momento eran presentados como ejemplos contrarios a lo dicho, fueran incluidos en el enunciado: "La incorporación de la(s) exepción(es) en una reformulación de la ley que las subsume" (ibidem: 32). Con ello, Sartori se opone de hecho a todos aquellos críticos de Duverger que no creen posible la existencia de "leyes sociológicas": Sartori logra la reformulación (dicho de forma simplificada) de la siguiente manera:

Ley 1: Si ningún tercer partido (a más de los dos grandes) alcanza la mayoría relativa de votos en una de las circunscripciones, entonces los sistemas electorales de representación por mayoría provocan un régimen bipartidista.

Ley 2: Si algunos de los terceros partidos (es decir, a más de los dos grandes partidos) alcanzan la mayoría relativa de los votos en circunscripciones uninominales, entonces al darse un sistema de mayoría relativa se produce un sistema multipartidista que se compone de la 
misma cantidad de partidos (a más de los dos grandes) que alcanzan esta concentración de votos.

Ley 3: Cuanto mayor sea el efecto de desproporción en un sistema electoral proporcional, tanto mayor será el efecto de reducción sobre el número de partidos; o dicho de forma más tajante: mientras menos partidos superen el umbral electoral natural (tamaño de la circunscripción) o el umbral artificial (barrera legal), menos partidos ingresarán al parlamento.

Ley 4: En sistemas electorales proporcionales, el mismo número de partidos que haya alcanzado el coeficiente electoral (el valor mínimo para alcanzar un escaño) puede alcanzar escaños.

Las condiciones necesarias de sus enunciados de ley son la estructura del sistema de partidos y la distribución geográfico-electoral de los votantes, siendo el sistema electoral condición suficiente para ello (Sartori, 1994: 45 y ss.).

Si uno lee las "leyes" detenidamente, se sorprenderá, más allá de las anotaciones sobre condiciones necesarias y suficientes, por su trivialidad. Éstas resumen de forma descriptiva, al definir el marco concreto de condiciones, aquellas configuraciones de factores de las que puede salir lógicamente en cada caso sólo el resultado indicado. Así, las leyes de Sartori se cierran ante cualquier posibilidad de falsación de la conexión causal que se le imputa, según Popper, una condición para decir que se trata de enunciados científicos y no solamente de ecuaciones definitorias. Aunque Sartori en ocasiones admite que en las ciencias sociales no puede haber leyes deterministas (ibidem: 32 ), no se puede negar que las leyes reformuladas por este autor son exactamente eso, pues por pura lógica excluyen la posibilidad de fracasar en la demostración empírica.

Ante este trasfondo se entiende la notable controversia entre Sartori y Rae, pues refleja el enfoque de cada cual. Sartori recalca la posibilidad ex-ante del pronóstico en ciencia política de las consecuencias que tienen los sistemas electorales con la siguiente tesis: "Los efectos de los sistemas electorales pueden ser adecuadamente predecibles y determinados" (ibidem: 29). En cambio, Rae afirma fríamente en su estudio ex-post sobre la conexión con base en algunos resultados electorales concretos: "No es fácil determinar la importancia de los efectos de las reglas electorales en la producción del observado patrón de competencia entre partidos" (Rae, 1967: 134). 
Para hacer justicia a Sartori, sus afirmaciones, sin embargo, deben interpretarse ante el trasfondo de su preocupación por mantener abierto el campo de la ingeniería política, para sí mismo y para la ciencia política en general. De esta manera se entiende su insistencia por investigar solamente una dimensión de la conexión causal que se imputa, es decir, que el sistema de partidos depende del sistema electoral, y de la previsibilidad de las consecuencias de los sistemas electorales sobre los sistemas de partidos. A esto se opone su afirmación expresada en varias ocasiones de que los sistemas de partidos, diferenciados en su estructura según el sistema de valoración dual entre "fuertes" versus "débiles", juegan un papel como factor en la relación causal entre sistema electoral y sistema de partidos que es adecuado para ejercer un efecto retroactivo sobre la variable clásicamente considerada como independiente. Sartori incluso constata: "El punto... es que los efectos de los sistemas electorales no pueden valorarse correctamente sin evaluar al mismo tiempo las propiedades de manipulación y canalización del sistema de partidos como tal" (Sartori, 1994: 37).

$\mathrm{Su}$ controversia con mi postulado de que las reformas que abarcan el tipo de sistema electoral son absolutamente inusuales (Nohlen, 1984: 128), también tiene su justificación más profunda en su inclinación por el asesoramiento político, pues, según Sartori:

Una profesión que ha sostenido durante mucho tiempo que los sistemas electorales no pueden provocar nada (ya que son producidos por la política, pero no causan política), o no ser modificados (el argumento de la "no opción”), y (lo más terrible de todo), cuyo canon ha mantenido sin vacilaciones que sus efectos no pueden predecirse con precisión o confianza - una profesión que ha sostenido durante mucho tiempo tales puntos de vista - no puede tener muchos consejos que ofrecer (Sartori, 1994: 24).

Sin embargo, mi experiencia en el asesoramiento político señala que las recomendaciones institucionales que no toman en cuenta el contexto, van a ninguna parte.

En la opción por uno u otro sistema electoral se expresa la preferencia de Sartori por aquellos sistemas que podrían tentativamente dirigir la estructura del sistema de partidos:

Los sistemas de mayoría absoluta y relativa funcionan, o en todo caso funcionan al máximo de su capacidad, cuando fomentan un sistema bi- 
partidista que produce, en suma, un gobierno con partido único "responsable". Pero esto generalmente no pasa... (Sin embargo) mantienen baja la fragmentación del sistema de partidos, por lo que son más propensos a propender gobiernos eficaces que en sistemas de representación proporcional (ibidem: 73).

En realidad, Sartori no confiesa francamente cuál de los sistemas electorales le parece mejor, pero: “... si hay un sistema electoral 'mejor', este es el sistema de segunda vuelta electoral en su amplia gama de adaptabilidad... con la condición, por supuesto, que ningún sistema electoral es el mejor para todas las ocasiones" (ibidem: 75).

\section{Arend Lijphart y el afán de la precisión cuantitativa}

Arend Lijphart se relaciona con Douglas W. Rae en dos sentidos. Por una parte, su interés cognitivo también se orienta hacia los efectos políticos que pueden tener los sistemas electorales, a cuyo efecto propone una diferenciación idéntica a la de Rae, en relación con la variable dependiente. Por otra parte, al igual que Rae está comprometido con el enfoque empírico-estadístico. En este sentido recalca que la obra de Rae sería "el libro más importante en el campo de los sistemas electorales comparados" (Lijphart, 1990: 481) y reconoce que ha sido "una fuente importante de inspiración" para su propio análisis (Lijphart, 1994: 11). Su objetivo es "volver a analizar el estudio clásico de Rae con datos más precisos, hipótesis más fuertes, y mejores métodos" (Lijphart, 1990: 481). En algunas conceptualizaciones este autor sigue a Rae, por ejemplo en la diferenciación entre efectos próximos y distantes (Lijphart, 1994: 70) o en aquella entre "partidos electorales y partidos parlamentarios" (ibidem: 77 y 81), así como en el supuesto relacionado con lo dicho y proveniente de Duverger de que el número de partidos depende de factores psicológicos, en el primero de los dos niveles, y de factores psicológicos y mecánicos, en el segundo nivel (ibidem: 72).

No obstante, Lijphart primero aduce que su antecesor de similar posición metodológica comete muchos errores: "De hecho, el libro sufre de un sinnúmero de debilidades conceptuales, metodológicas y empíricas, las cuales son tan graves y numerosas que ponen en duda 
todas las conclusiones de Rae" (Lijphart, 1990: 481). Entre otras cosas, critica que Rae no haya estudiado, como una variable, el tamaño del parlamento, a pesar de que él mismo hubiera aludido a la importancia del tema (Lijphart, 1994: 12) y que no haya tomado en cuenta los umbrales ("thresholds", ibidem: 14). Y, además, hay una diferencia radical con Rae, en cuanto a la unidad de análisis: "En contraste con el tratamiento que Rae da a cada elección como un caso diferente, mi unidad de análisis es el sistema electoral" (Lijphart, 1990: 482). "Mis casos son setenta y cinco sistemas electorales, definidos como un grupo de reglas electorales esenciales e invariables en las que una o más elecciones sucesivas se llevan a cabo" (Lijphart, 1994: 7, 13). Fundamenta su decisión en que "las elecciones que se dan bajo las mismas reglas no son realmente casos independientes sino meras operaciones repetitivas del mismo sistema electoral" (Lijphart, 1990: 482). De esta manera, Lijphart desglosa la conexión entre sistemas electorales concretos y sistemas concretos de partidos, con lo que descuida que en cada elección la constelación en la competencia de partidos (posiblemente) cambie. Con ello acepta que la dependencia contextual de los efectos de los sistemas electorales no sea tomada en cuenta ( $c f r$. Grotz, 2000).

Lijphart diferencia los sistemas electorales sobre la base de elementos técnicos (dimensions) y toma como dimensiones más relevantes aquellas que producen el mayor efecto sobre la proporcionalidad de los resultados electorales: la fórmula electoral, es decir, las reglas de mayoría o reglas proporcionales, y el tamaño de la circunscripción (1994: 10). Como una dimensión adicional importante, Lijphart trae a colación el umbral electoral (electoral threshold). En primera instancia, entiende por este término la barrera legal, amplía posteriormente el concepto hacia el umbral efectivo (effective threshold) al integrar el umbral natural (natural threshold) que resulta del tamaño de la circunscripción, en el concepto operacional (ibidem: 12, 25 y ss.). Finalmente añade el tamaño del parlamento (assembly size) como cuarta dimensión, de igual importancia en su opinión. Esta introducción conduce de paso a que se amplíe de forma novedosa el término sistema electoral.

Sin embargo, el estudio del efecto de los sistemas electorales sobre los sistemas de partidos ya no se trata directamente. Más bien, la variable dependiente se subdivide en efectos de proporcionalidad y efectos de fragmentación. Además, se realza la primera variable parcial: "La desproporcionalidad es el fenómeno central importante" (ibidem: 75). Lijphart fundamenta este acento con el hecho de que casi todos los 
sistemas electorales, en cierta medida, tienden a la desproporcionalidad, a pesar de que la proporcionalidad posiblemente sea su objetivo: “... Hay casi un acuerdo universal respecto a que la proporcionalidad electoral es el objetivo principal de los sistemas electorales y el principal criterio por el que deben ser juzgados" (ibidem: 140). Instrumentaliza así el reconocimiento mundial del principio de representación proporcional, para legitimar su concentración en el efecto mesurable de los sistemas electorales.

Todas estas decisiones analíticas tienen que ver con el método estadístico de investigación. Lijphart conceptualiza y prepara el objeto de su análisis de tal manera que se adecue lo más óptimamente posible a su enfoque de estudio. Queda todavía mucho por cuestionar: el novedoso término para el sistema electoral, integrando el tamaño del parlamento en su definición, que en realidad no hace sentido, ni en sistemas electorales mayoritarios en circunscripciones uninominales ni en grandes parlamentos con más de 100 escaños, o la conjunción de la barrera legal y natural, cuando cada cual presenta un efecto diferente de desproporción; en el primer caso, la desventaja se da solamente para partidos que no alcanzan el número requerido de votos; en el segundo caso, afecta por lo general (dependiendo del tamaño de la circunscripción) a todos los partidos, menos al que logra la mayoría de votos, o la identificación de efectos mecánicos (Duverger) con efectos próximos (Rae) y psicológicos (Duverger) con efectos distantes (Rae) (Lijphart, 1990: 483; 1994: 70 y 82), siendo que Duverger solamente tiene en mente las causas o el origen y Rae las consecuencias o el efecto de ambos fenómenos, etcétera. ${ }^{8}$

En cuanto a los resultados de Lijphart, saltan primero a la vista algunas de sus afirmaciones con un contenido casi obvio: "La desproporcionalidad generalmente favorece a los partidos más grandes en lugar de los partidos más pequeños" (Lijphart, 1994: 128), o: los sistemas electorales mayoritarios se diferencian de los sistemas electorales proporcionales por tener una limitante efectiva significativamente más difícil de superar; o: los resultados electorales mayoritarios logran una desproporcionalidad más alta con respecto a los sistemas electorales proporcionales, o: "cuanto más alto es el umbral, más alta

8 Es interesante observar que Lijphart en este su libro clásico se refiere a Duverger sólo respecto a la distinción entre estos dos factores y al factor presidencialismo en relación con la fragmentación del sistema de partidos, ni una palabra sobre las "leyes sociológicas". 
es la frecuencia de mayorías parlamentarias" (ibidem: 142). Además se demuestra que el tamaño del parlamento no es una variable relevante: "el tamaño del parlamento... no afecta significativamente las variables de los sistemas de partidos" (ibidem: 117).

Por supuesto, hay que clasificar los resultados importantes de Lijphart según sus dos variables dependientes. Pues los efectos de los sistemas electorales tienen resultados muy diferentes, dependiendo si se refieren a la desproporción o al sistema de partidos. Para cada una de las dos variables dependientes, el autor formula dos tesis, diferenciando su posición respecto de la de Rae. En relación con la desproporcionalidad que no sería una manifestación casual, sino un patrón regular, con el cual normalmente los partidos grandes estarían sobrerrepresentados y los partidos pequeños sistemáticamente subrepresentados (ibidem: 24), dice: “(1) La relación entre la fórmula electoral y la proporcionalidad en los resultados electorales es mucho más fuerte de lo que Rae plantea; (2) la relación entre la magnitud de las circunscripciones y la proporcionalidad es también más fuerte, sobre todo en lo que se refiere a los efectos de los sistemas con distribución de los escaños a dos niveles (que Rae asegura no tener efecto)" (Lijphart, 1990: 482). Pero la desproporcionalidad es solamente un indicador débil sobre el número de partidos en un sistema de partidos, no solamente a nivel del electorado, sino también a nivel del parlamento, aunque en este último sea menos manifiesto (ibidem: 493). Con referencia al sistema de partidos, Lijphart formula las siguientes dos tesis, nuevamente para diferenciar su pensamiento del de Rae: (1) "La relación entre la fórmula electoral y el grado de multipartidismo es mucho más débil de lo que Rae plantea, (2) de la misma manera, la magnitud de los distritos y el multipartidismo son mucho menos fuertes y estrictamente relacionados que lo que Rae afirma" (ibidem: 482). Lijphart también constata efectos recíprocos (a two way relationship): "la desproporcionalidad y el multipartidismo se afectan mutuamente en direcciones opuestas: La desproporcionalidad disminuye la fragmentación de partidos en el ámbito parlamentario, y viceversa: el multipartidismo, en cambio, fomenta la desproporcionalidad entre votos y escaños" (Lijphart, 1994: 77). Asimismo reconoce al sistema de partidos "como la variable independiente y la desproporcionalidad como la variable dependiente" (idem), pero, solamente al mirar la conexión estadística, no en vista de que el sistema de partidos decide sobre la selección del sistema electoral. 
Por consiguiente, al comparar las dos variables dependientes y la influencia que ejerce el sistema electoral sobre éstas, Lijphart llega a la conclusión: "La relación entre el sistema electoral y los... sistemas de partidos... es mucho más débil que la que hay entre el sistema electoral y el grado de desproporcionalidad" (ibidem: 141). Haciendo un resumen total: "Los sistemas electorales muestran grandes y previsibles diferencias respecto a la desproporcionalidad, menores diferencias respecto al multipartidismo que son el efecto directo de la desproporcionalidad, y aun menores diferencias respecto a multipartidismo electoral debido a los cálculos estratégicos de las élites y los votantes" (Lijphart, 1990: 493). Y constata al finalizar: "El sistema electoral no es un instrumento tan fuerte para la conformación de sistemas de partidos" (Lijphart, 1994: 141). Con esta tesis, finalmente, se pronuncia sobre la pregunta que movió el estudio clásico de los sistemas electorales, a partir del enfoque empírico-cualitativo y que retomó actualizándolo Giovanni Sartori, a saber, la pregunta sobre los efectos del sistema electoral sobre el régimen de partidos.

Sin embargo, Lijphart no explica la controversia planteada en esta tesis con las de Duverger y Sartori. Al contrario, aprueba la diferenciación que hace Sartori entre sistemas electorales fuertes (sistemas mayoritarios) y débiles (sistemas proporcionales) (ibidem: 82) para, evidentemente, plantearla dentro de la pregunta más precisa sobre aquellas variables que provocan la desproporcionalidad, es decir que son "fuertes". "Claramente, el umbral efectivo es un fuerte instrumento para los ingenieros electorales, pero la fórmula de pluralidad (con umbral inherente muy alto) es el principal instrumento" (ibidem: 143). Con frecuencia la desproporcionalidad que de hecho depende fuertemente del sistema electoral asume el papel de variable dependiente, en vez del sistema de partidos:

Teniendo en cuenta los muchos factores que están fuera del sistema electoral pero que afectan el grado de proporcionalidad - tales como las escisiones ("cleavages") políticas en una sociedad, el tamaño relativo de los grupos sociales más importantes, así como la distribución regional de los votos- es asombroso que hasta dos tercios de la variación en la desproporción se explique por el sistema electoral por sí solo (ibidem: 116).

El llamado a los ingenieros de sistemas electorales para que ahora hagan uso de la caja de herramientas y se pongan a fabricar sistemas de 
partidos no llega a concretarse. Por cierto, Lijphart toma como punto de partida la tesis de Sartori sobre el carácter manipulador del sistema electoral (ibidem: 139) para preguntarse, entre otros puntos, también: “¿hasta qué punto los políticos son capaces o están dispuestos a manipular los sistemas electorales?" Sin embargo, no debate realmente esta pregunta, sino que observa más bien que el "cambio de la representación proporcional al sistema de mayoría relativa o viceversa" no sucedió en el set de países que él estudió entre 1945-1990 (ibidem: 143) y se suma a mi tesis (Nohlen, 1984: 218), a la que denomina "una de las más conocidas generalizaciones acerca de los sistemas electorales", éstos "tienden a ser muy estables y resistentes al cambio" (Lijphart, 1994: 52).

Al plantear la opción entre sistemas electorales, Lijphart es unívoco, más aun en relación con la recomendación política dada a jóvenes democracias: "Para las nuevas democracias, mi recomendación sería la de dar la máxima prioridad a la selección de un sistema de representación proporcional que sea simple de entender y manejar y que tenga un alto, pero no necesariamente perfecto, grado de proporcionalidad". Incluso pasa a los detalles técnicos: "Desde el criterio de simplicidad varias recomendaciones adicionales se pueden derivar: distritos plurinominales electorales que no sean demasiado grandes (más o menos en el rango de 7 a 10 escaños), la lista de representación proporcional en vez del voto único transferible, y listas cerradas o casi cerradas" (2008: IX).

\section{Resumen}

En lo siguiente quiero revisar a modo de comparación los resultados de cada una de las contribuciones analizadas, para hacer más visible cuánto debate, de qué tipo y con qué intensidad se expresan realmente las controversias sobre los sistemas electorales. Las diferencias en el interés cognitivo no justifican por sí solas una controversia. Pero permiten inferir de allí sobre la importancia que en cada caso se confiere al tema del sistema electoral. En general, en el centro del debate está ya sea el sistema electoral, o el sistema de partidos; es decir, pueden ser los efectos del sistema electoral sobre el sistema de partidos, o los diversos factores que ejercen una influencia sobre el sistema de partidos, y entre estos, el sistema electoral. Duverger, Rokkan y Sartori se inte- 
resan en primera instancia por el sistema de partidos, pero reconocen que el sistema electoral es un factor importante (Duverger, Rokkan), incluso el más importante, para direccionarlo (Sartori). Rae y Lijphart se enfocan en el sistema electoral para descubrir cuál es la influencia mesurable del sistema electoral y algunos de sus componentes.

En estrecha relación con ello también se plantea la pregunta, si posiblemente el sistema de partidos también influye sobre el sistema electoral y, esto, por dos caminos: cuando los partidos seleccionan el sistema electoral y cuando el sistema de partidos influye sobre los efectos que puede tener el sistema electoral. Solamente Rokkan formula este primer caso; Duverger y Lijphart al menos consideran el segundo caso. Con gran decisión, Sartori defiende la constelación tradicional sobre las variables investigadas: el sistema electoral como variable independiente y el sistema de partidos como variable dependiente.

Las diferencias en el procedimiento metodológico como tal tampoco justifican una controversia, a menos que los resultados del análisis se deban a estas diferencias. Rae, un convencido del método empírico-estadístico, ajusta cuentas a partir de esta posición con todos los estudios anteriores planteados desde el punto de vista histórico-cualitativo. Resulta, sin embargo, notable que la controversia articulada de manera más decidida haya sido protagonizada, en cada caso, por investigadores en contra de sus antecesores que tuvieran un procedimiento metodológico similar. Hablamos de la crítica de Lijphart con respecto a Rae, en cuanto al diseño investigativo empírico-estadístico; y a la crítica de Sartori con respecto a Duverger, en relación con la formulación de leyes sobre los hallazgos investigativos que se levantaron cualitativamente.

Ahora bien, la controversia no puede reducirse únicamente a las contradicciones formuladas. No siempre los estudiosos de los sistemas electorales se tomaron en cuenta entre sí. Es, por ejemplo, el caso de Rokkan que no considera a Duverger. Tampoco exteriorizan la controversia objetiva, que como en el caso de Lijphart en relación con Sartori prefiere presentar las coincidencias. Conforme con esto, el estudio comparativo debe incluir similitudes y diferencias, ya sea que éstas hayan sido articuladas o no.

Veamos entonces primero el alcance de la relación que es el objeto de estudio. El alcance es amplio en Duverger, Rokkan y Sartori; se trata del desarrollo democrático como tal, a ratos también en relación 
con el supuesto sobre una enorme envergadura política al momento de decidir sobre el sistema electoral —incluso en Rokkan, a pesar de que este autor considera que el sistema electoral es más bien una variable dependiente-. En cambio, en los casos de Rae y Lijphart, el alcance dentro de su programa de investigación de los sistemas electorales es más bien reducido. Tratan única y exclusivamente los efectos que tiene un sistema electoral en los parámetros mesurables sobre la representación. El hecho de que Lijphart, en otros estudios, expanda de forma decidida su enfoque y lo amplíe integrando aspectos normativos, aquí no es parte del debate (véase Lijphart, 2012).

A continuación, nos interesa el tratamiento que se da a lo que se considera la variable independiente. En Duverger y Rokkan, el sistema electoral en sí aparece como una unidad poco o nada descifrada. Se hace la diferenciación — de forma, por cierto, muy clásica - entre sistemas electorales de mayoría absoluta, mayoría relativa y representación proporcional. En Rae y Lijphart, en cambio, se desglosa el sistema electoral en diversos componentes, estudiados cada uno según sus efectos. En sus estudios, sin embargo, se realizan dudosas operacionalizaciones, a fin de llegar a resultados que sean mesurables y valorables, tomando como máxima su validez estadística.

Acto seguido, observamos el tratamiento dado a la variable dependiente, que se modifica también con relevantes consecuencias para el alcance y la relevancia sobre los resultados del análisis. Duverger y Rokkan observan los sistemas de partidos como un todo y los diferencian al clasificarlos por el número de partidos. Sartori amplía el espectro tipológicamente, al considerar algunas características adicionales. Pone mayor énfasis en las características cualitativas del sistema de partidos, se pregunta por la "relevancia sistémica" (systemic relevance) de los partidos políticos. Rae y Lijphart, en cambio, se quedan con la definición matemático-cuantitativa del sistema de partidos. Por otra parte, clasifican la variable dependiente por áreas de impacto y profundidad del efecto. Ambos autores diferencian entre proporcionalidad o desproporcionalidad de votos y escaños por una parte, y el número de partidos o, en su caso, la fragmentación del sistema de partidos, por la otra. Con sus medios metodológicos se acercan primero a la cuestión de la desproporción, pues así pueden fácilmente calcular matemáticamente y presentar a nivel numérico los efectos del sistema electoral y sus diversos componentes. En segunda instancia 
recién aparece la clásica pregunta sobre el sistema de partidos, para cuya resolución no existen las mismas entradas metodológicas.

No habría que seguir cuestionando esta traslación del interés cognitivo, si los resultados solamente llegaran a una mayor exactitud, sin por ello perder relevancia. Rae, por lo demás, diferencia de manera orientadora entre efectos próximos y distantes en los sistemas electorales. El resultado científico será entonces que se podrán determinar con facilidad los efectos inmediatos del sistema electoral, pues el tamaño de la circunscripción está en estrecha correlación con el grado de proporcionalidad. Pero los efectos lejanos son poco predecibles. Rae además constata que la desproporcionalidad no es un buen indicador para la estructura del sistema de partidos. Aunque cada uno de los efectos ejercidos por los componentes del sistema electoral son detallados precisamente por Lijphart en su controversia con Rae, esto no cambia en nada el hecho de que el hallazgo científico-cognitivo principal se logra en un campo que no aporta mayormente a la pregunta clásica de los sistemas electorales, es decir, la posible relación causal existente entre sistema electoral y sistema de partidos. Por cierto, se relativiza la importancia del sistema electoral en el sistema de partidos, pero esto ya resultó de las fuertes críticas al "supuesto Duverger" por parte de sus oponentes científicos. Y esta crítica no apunta solamente a la correlación entre variables mesurables, sino al gran todo, a todos los factores que influyen en la estructura del sistema de partidos. Rae lo resalta y Lijphart lo menciona alguna vez, pero no son parte de su programa de investigación. Se puede, por tanto, llegar a la conclusión que la precisión empírico-estadística se logra, a costa del alcance y la relevancia de los enunciados.

¿Cuál es, entonces, la posición asumida por estos autores con respecto a la cuestión de la causalidad? ¿Ciertos sistemas electorales realmente impactan en las características de los diferentes sistemas de partidos? Solamente Sartori se mantiene en la posibilidad de la existencia de las leyes sociológicas. Pero integrando condiciones adicionales al enunciado de una ley que por lógica no permiten llegar a otro resultado que ya no sea falsacionable. Incluso Duverger deja de lado sus "leyes sociológicas". Esta posición mayoritaria naturalmente no excluye que, a pesar de todas las relativizaciones, prevalezcan los supuestos monocausales del estudio, respaldados en Duverger sobre todo con la recepción histórica de sus fórmulas, en Rae y Lijphart condicionados por el diseño de su análisis. Estos dos investigadores solamente tema- 
tizan variables que pertenecen ya sea al sistema electoral o al sistema de partidos y estudian la correlación entre ambos fenómenos solamente en una dirección. Incluso Rokkan y Sartori rinden tributo a un cierto monocausalismo. Sartori se enfoca en el sistema electoral como la causa exclusiva para defender la utilidad del electoral engineering en ciencia política. En el caso de Rokkan, aunque su argumentación sea multicausal, en realidad todo depende de las líneas de conflicto; en su caso, el sistema electoral juega principalmente el papel de variable dependiente. Pero el monocausalismo en el tratamiento del objeto de estudio, justificado de diversas formas, simplemente no es idéntico a una afirmación de contenidos del mismo tipo. Al contrario, las investigaciones empírico-cuantitativas, por ejemplo, aunque trabajen con correlaciones, también indican que no se puede probar una relación unívoca de efecto entre sistema electoral y sistema de partidos. Estos resultados coinciden con mis estudios histórico-empíricos de los sistemas electorales en todo el mundo (véase la bibliografía). Esto no significa, de modo alguno, que la ciencia política no pudiera pronunciarse sobre la relación analizada y que, por ello, tal como expresara Sartori sus temores, sería incapaz de presentar resultados políticos de relevancia directa en sus conclusiones. En vez de recomendaciones abstractas habrá más bien que elaborar recomendaciones a la medida para situaciones concretas de factores para diversos países y épocas.

Si de esta manera se debe conocer el contexto social y político de un país para poder dar recomendaciones normativas de utilidad, entonces se plantea obviamente la pregunta, si todavía se puede optar en general por un tipo de sistema electoral, al estilo de la antigua controversia entre representación por mayoría y representación proporcional de los clásicos. Duverger definitivamente erigió a los sistemas de mayoría (relativa y absoluta) como los best systems. Rokkan y Rae no se expresan en relación con la mejor opción; se mantienen dentro del análisis. Rokkan lo hace seguramente porque considera que la opción por un sistema electoral depende de los actores políticos, las alianzas y los acuerdos, y considera además que ya ha sido decidida con el congelamiento del sistema de partidos en sus países estudiados. Tanto Rae como Lijphart excluyen la pregunta sobre la opción en sus estudios clásicos; las reflexiones normativas no caben en su enfoque de análisis empírico-estadístico. Lijphart, evidentemente, no tuvo empacho en otro momento relacionado con su teoría de la concordancia (Lijphart, 1999 y 2012) y en sus recomendaciones para las democracias jóvenes 
(Lijphart, 1990 y 2008) de expresar su preferencia por la representación proporcional. Sartori se opone decididamente a la recomendación de Lijphart, en general, se opone a su sesgo (Sartori, 1994: 69 y ss.) y, en la teoría, es de la opinión que el mejor sistema electoral sería aquel que mejor se adapta. Simultáneamente, sin embargo, expresa su apego por el sistema de mayoría absoluta y en la práctica interviene en algunos países para que ésta sea introducida. Yo abogo definitivamente por aceptar la posición relativa mostrada por Sartori en la teoría. La pregunta sobre la opción que se plantea en ciencia política en la actualidad no es de tipo filosófico-teórica sobre el Estado, sino una cuestión histórico-empírica con un trasfondo de teoría del Estado o, de ser el caso, constitucional.

Estas reflexiones conducen a la pregunta final sobre el estado actual de los avances científicos dentro del estudio de los sistemas electorales. Los representantes de un enfoque comparativo-cuantitativo más nuevo recalcan que recién desde su aparición, el estudio de los sistemas electorales ha evolucionado de un estado cualitativo-rudimentario a una ciencia madura (Shugart, 2008: 25 y sss.). Sin embargo, que un enfoque se levante sobre los demás, dogmatizando su propio parámetro cuantitativo de forma nada crítica, no es algo que se acepte sin réplica. Sartori plantea lacónicamente la pregunta que da en el blanco:

¿Cómo puede ser que los enfoques cuantitativos posteriores puedan decir que sacan del ruedo a los anteriores, de tipo cualitativo, cuando el desarrollo defectuoso posterior causado por éstos resulta evidente y se expresa al reemplazar la relevancia por la precisión?... la masiva pérdida de concreteness que provocan las fórmulas matemáticas es una gran desventaja. Es cierto, mi concreteness es a veces flexible e impresionista, pero no puede ser tan desorientador como una precisión matemática que a menudo solo es una falsa precisión fabricada por la medición (Sartori, 1994: 36).

Los avances al interior de los diversos enfoques hablan el mismo idioma, pues en cada caso fuerzan la manera de obtener avances científicos dentro de su metodología. Para aquellos empíricos-estadísticos se puede determinar que es la precisión matemático-estadística y no la mayor relevancia, la que alimenta la creencia en el progreso. Esto se demuestra en el intento de Lijphart, sin lugar a dudas exitoso, de sobrepasar a Rae en lo referente a la precisión. En cambio, el desarrollo del estudio empírico-cualitativo de los sistemas electorales se ha 
mantenido dentro de la pregunta sobre la relevancia. Lo que también rige para las afirmaciones que por su parte desencadenaron fuertes críticas, como por ejemplo, el intento de Sartori de reformular las leyes sociológicas de Duverger. Pues, dentro de todo, Sartori menciona dos factores inherentes al contexto que también definen los efectos de los sistemas electorales, aun cuando los haya incluido en las leyes como marco de condiciones, al decir "si pasa..., entonces": la dispersión regional del electorado y el grado de institucionalización de los partidos o del sistema de partidos.

En realidad, Sartori reconoce así el poder de los factores sociales y políticos concretos en la interdependencia de acción entre sistemas electorales y sistema de partidos que yo, por mi parte, recalco aún más, entre otros, en vista también de la selección del sistema electoral que considero dependiente del sistema de partidos, o en su caso, de las estructuras más profundas y dinámicas sociales y políticas, a la Rokkan. Aquí coincido con Richard Rose que igualmente subraya "la gran fuerza del contexto nacional frente a las propiedades del sistema electoral" (Rose, 1984: 78). Aunque acepto con ello la posibilidad de que los enunciados que conducen a abstracciones sobre los efectos de los sistemas electorales sean aún más limitados de lo que plantea Sartori, esto no incluye negar la posibilidad de que conociendo las condiciones concretas del contexto se puedan hacer afirmaciones sobre los presuntos efectos de los diferentes sistemas electorales. Pues la cuestión de los sistemas electorales no se refiere sólo a su autoimpacto abstracto, sino a sus efectos en contextos sistémicos combinados con otros factores, tomando en cuenta también la inversión de la supuesta relación causal. En otra oportunidad, ya recomendé, por tanto, no dedicar la mayor atención al sistema electoral, en el momento de realizar el estudio de sistemas electorales, sino dedicarse con igual intensidad a revisar los factores del contexto que refuerzan, distorsionan o socavan los efectos inherentes lógico-abstractos de los sistemas electorales, y a trabajar en su sistematización (Nohlen, 2010a).

\section{Bibliografía}

Bogdanor, V., 1983, "Conclusion: Electoral Systems and Party Systems”, en Bogdanor, Vernon y Butler, David (eds.), Democracy 
and Elections, Electoral Systems and their Political Consequences, Cambridge, Cambridge University Press.

Cox, G. W., 1997, Making Votes Count, Cambridge, Cambridge University Press.

Duverger, M. et al., 1950, L'influence des systèmes électoraux sur la vie politique, París, Armand Colin.

Duverger, M., 1951, Les partis politiques, París, Armand Colin (1958, 3a. ed.).

-_-, 1954, Political Parties, Nueva York, Wiley

- - , 1955, Institutions politiques et droit constitutionnel, París, Presses Universitaires de France (cuarta ed. 1968).

- - - 1957, Los partidos políticos, México, Fondo de Cultrura Económica (2001, 17a. ed.).

-_-, 1959, Die politischen Parteien, Tubinga, Mohr.

_-_, 1968, Sociología política, Barcelona, Ariel.

- - , 1984, "Which is the Best Electoral System?", en Lijphart, A. y Grofman, B. (eds.), Choosing an Electoral System. Issues and Alternatives, Nueva York, Praeger.

- - - 1986, “Duverger's Law: Forty Years Later”, en Grofman, B. y Lijphart, A. (eds.), Electoral Laws and their Political Consequences, Nueva York, Agathon Press.

FlorA, P., 1981, "Stein Rokkans Makro-Modell der politischen Entwicklung Europas”, Kölner Zeitschrift für Soziologie und Sozialpsychologie 33.

Gallagher, M. y Mitchell, P. (eds.), 2008, The Politics of Electoral Systems, 2a. ed., Oxford, Oxford University Press.

Grofmann, B. y Lijphart, A. (eds.), 1986, Electoral Laws and their Political Consequences, Nueva York, Agathon Press.

Grotz, F., 2000, Politische Institutionen und post-sozialistische Parteiensysteme in Ostmitteleuropa [Instituciones políticas y sistemas de partidos postsocialistas en Europa oriental central], Opladen, Leske \& Budrich.

HäBerle, P., 1981, Klassikertexte im Verfassungsleben, [Textos de clásicos en la vida constitucional], Berlín-Nueva York, de Gruyter.

InTERNATIONAL IDEA (ed.), 1997, The International IDEA Handbook of Electoral System Design, Stockholm, International IDEA.

Kunn, Th., 1971, La estructura de las revoluciones científicas, México, Fondo de Cultura Económica. 
Lijphart, A., 1984, "Advances in the Comparative Study of Electoral Systems", World Politics 36.

_- - 1984, "Trying to Have the Best of Both Worlds: Semi-Proportional and Mixed Systems", en Lijphart, A. y Grofman, B. (eds.), Choosing an Electoral System. Issues and Alternatives, Nueva York, Praeger.

- — , 1985, "The Field of Electoral Systems Research: A Critical Survey", Electoral Studies 4 (1).

-_- 1988, The Political Consequences of Electoral Laws, 1945-1985.

A Critique, Re-Analysis, and Update of Rae's Classic Study, IPSAPaper XIV World Congress, Washington, D. C.

-_- 1990, “The Political Consequences of Electoral Laws, 19451990", American Political Science Review 84 (2).

_-_, 1991, "Constitutional Choices for New Democracies", Journal of Democracy, 2 (1).

-_-, 1994, Electoral Systems and Party Systems. A Study of TwentySeven Democracies, 1945-1990, Oxford (versión española, 1995: Sistemas electorales y sistemas de partidos, Madrid, CEC).

- - , 1999, Patterns of Democracy, New Haven-London (2a. ed., 2012).

- - , 2008, "Forword", en Gallagher, M. y Mitchell, P. (eds.), The Politics of Electoral Systems, Oxford, Oxford University Press.

- - - y Grofman, B. (eds.), 1984, Choosing an Electoral System. Issues and Alternatives, Nueva York, etc., Agathon Press.

- - - y Waisman, C. (eds.), 1996, Institutional Design in New Democracies. Eastern Europa and Latin America, Boulder, Oxford.

Lipset, S. M., 1985, Consensus and Conflict. Essay in Political Sociology, Oxford.

- - - y Rokkan, S. (eds.), 1967, Party Systems and Voter Alignments, Nueva York, Free Press.

- - - y Rokkan, S., 1967, "Cleavage Structures, Party Systems, and Voter Alignments: An Introduction”, en Lipset, S. M. y Rokkan, S. (eds.), Party Systems and Voter Alignments. Cross National Perspectives, Nueva York, The Free Press.

Lipson, L., 1953, “The Two-Party System in British Politics”, American Political Science Review 47.

Mackenzie, W. J. M., 1964, Free Elections. An Elementary Textbook, 2a. ed., London. 
Mackie, T. H. y Rose, R. (eds.), 1983, The International Almanac of Electoral History, Londres, Macmillan ( $\left.{ }^{2} 1983\right)$.

Nohlen, D., 1969, Begriffliche Einführung in die Wahlsystematik, en Sternberger, D. y Vogel, B. (eds.), Die Wahl der Parlamente und anderer Staatsorgane, Berlín, de Gruyter.

_-_, 1978, Wahlsysteme der Welt [Sistemas electorales del mundo], Múnich, Pieper.

_-_, 1981, Sistemas electorales del mundo, Madrid, Centro de Estudios Constitucionales.

- - , 1984a, Two Principles of Representation, en Lijphart, A. y Grofman, B. (eds.), Choosing an Electoral System. Issues and Alternatives, Nueva York, Praeger.

- - - 1984b, "Changes and Choices in Electoral Systems", en LIJPhart, A. y Grofman, B. (eds.), Choosing an Electoral System. Issues and Alternatives, Nueva York, Praeger.

_-_, 1984c, "Los sistemas electorales entre la ciencia y la ficción. Requisitos históricos y teóricos para una discusión racional", Revista de Estudios Políticos, 42.

-_-, 1995, Electoral System: Options for Pakistan, Islamabad, Friedrich Ebert-Stiftung.

_- - 1996, "La trilogía sistema de gobierno, sistema electoral y sistema de partidos políticos", en Lipset, S. M. et al., Apuntes para una reflexión sobre la democracia. Tres ensayos, San José, Costa Rica, IIDH-CAPEL.

-_-, 1997, Sistemas electorales en Europa del Este. Génesis, crítica, reforma, Colección Temas de la democracia 3, México, IFE.

-_- , 1998, Sistemas electorales y partidos políticos, México, Fondo de Cultura Económica (3a. ed. revisada y aumentada, 2004).

-_-, 2000, "Binominal electoral system", en Rose, R. (ed.), International Encyclopedia of Elections, Washington, D. C., Congressional Quarterly Press.

- - , 2003, El contexto hace la diferencia. Reformas institucionales y el enfoque histórico-empírico, ed. por C. Zilla, Mexico, UNAM.

- - , 2004, Sistemas electorales y partidos políticos, México, Fondo de Cultura Económica.

-_- , 2006, El intitucionalismo contextualizado. La relevancia del contexto en el análisis y diseño institucionales, editado e introducido por R. Ortiz Ortiz, México, Porrúa-UNAM. 
-_- 2006a, "La reforma del sistema binominal desde una perspectiva comparada”, Revista de Ciencia Política 26 (1).

_-_, 2008, Sistemas electorales en su contexto, ed. y prólogo de J. Reynoso Núñez, México, UNAM.

_-_, 2009a, "La reforma necesaria al sistema electoral alemán. El principio de igualdad de logro del voto como idée fixe en la sentencia del Tribunal Constitucional Federal del 3 de julio de 2008”, Justicia Electoral, Tercera Época, vol. 1, núm 4.

-_- , 2009, Wahlrecht und Parteiensystem [Derecho electoral y sistema de partidos], Opladen, Leske \& Budrich.

- - , 2010a, Wahlen und Wahlsysteme [Elecciones y sistemas electorales], en Lauth, H.-J. (ed.), Vergleichende Regierungslehre. Eine Einführung, 3a. ed., Wiesbaden, VS-Verlag.

- — , 2010b, "Elections and Electoral Systems", en Nohlen, D. y Stöver, Ph. (eds.), Elections in Europe. A Data Handbook, BadenBaden, Nomos.

-_- , 2012, Gramática de los sistemas electorales. Una introducción a la ingeniería de la representación, Quito, Instituto de la Democracia. ___, 2013, "Die Politik des Sonderweges. Wahlsysteme als Rechtsfrage [La política del camino especial. Sistemas electorales como cuestión jurídica]", en Armingeon, K. (ed.), Parteien und Demokratie, por aparecer.

- - - (ed.), 2005, Elections in the Americas, 2 vols., Oxford, Oxford University Press.

- - - et al., 2000, "Electoral Systems in Independent Countries", en

Rose, R. (ed.), International Encyclopedia of Elections, Washington, D. C.

-_- et al., 2006, Diccionario de Ciencia Política. Conceptos, métodos, teorías, 2 vols., México, Porrúa-El Colegio de Veracruz.

- - - et al. (eds.), 2001, Elections in Asia and the Pacific, 2 vols., Oxford, Oxford University Press.

- - - y Kasapović, M., 1996, Wahlsysteme und Systemwechsel in Osteuropa [Sistemas electorales y cambios de sistema en Europa oriental], Opladen, Leske \& Budrich.

Nohlen, D. et al. (eds.), 1999, Elections in Africa, Oxford, Oxford University Press.

Nohlen, D. y Nohlen, N., 2007, "El sistema electoral alemán y el Tribunal Constitucional Federal. La igualdad electoral al debate-con 
una mirada a Venezuela”, Revista de Derecho Público, 109, eneromarzo.

Nohlen, D. et al. (eds.), 1998, Tratado de Derecho Electoral Comparado de América Latina, México, Fondo de Cultura Económica.

Nohlen, D. y Stöver, Ph. (eds.), 2010, Elections in Europe, Baden-Baden, Nomos.

Nohlen, D. et al. (eds.), 2007, Tratado de Derecho Electoral Comparado de América Latina, 2a. ed., México, Fondo de Cultura Económica.

Pappi, F. U., 1989, “Konfliktlinien [Líneas de conflicto]”, en Nohlen, Dieter (ed.), Pipers Wörterbuch zur Politik, t. 1, Munich, Pieper.

Rae, D. W., 1967, The Political Consequences of Electoral Laws, New Haven \& Londres, Yale University Press ( $\left.{ }^{2} 1971\right)$.

_- - 1977, Leyes electorales y sistemas de partidos políticos. Estudio comparativo, Madrid, Ediciones CITEP.

Rokkan, S., 1968, “Electoral Systems”, en Sills, D. L. (ed.), International Encyclopedia of the Social Sciences, Nueva York, vol. 5. Reprint of a revised version en Rokkan, S., Citizens, Elections, Parties, Nueva York, 1970.

- - , 1970, Citizens, Elections, Parties: Approaches to the Comparative Study of the Process of Development, Oslo, Universitetsvorlaget.

-_-, 2000, Staat, Nation und Demokratie in Europa. Die Theorie Stein Rokkans aus seinen gesammelten Werken rekonstruiert und eingeleitet von Peter Flora [Estado, Nación y Democracia en Europa. La teoría de Stein Rokkan a partir de sus trabajos compilados, reconstruidos e introducidos por Peter Flora], Francfort del Meno, Suhrkamp.

Rose, R., 1982, Choice in Electoral Systems. The Political and Technical Alternatives, en: Studies in Public Policies, 108, StrathclydeGlasgow

- - - (ed.), 2000, International Encyclopaedia of Elections, Washington D. C.

Sartori, G., 1976, Parties and Party Systems. A Framework for Analysis, Londres, Cambridge University Press.

_-_, 1983, 1986, “The Influence of Electoral Systems. Faulty Laws or Faulty Methods", 1983 mimeo, 1986 en Grofman, B. y Lijphart, A. (eds.), Electoral Laws and Their Political Consequences, Nueva York, Agathon Press. 


\section{Millan.}

1994, Comparative Constitutional Engineering, London, Mac-

-_-, 2003, "La transición de México, ¿Hacia dónde?”, en id., Ingeniería constitucional comparada, México, Fondo de Cultura Económica.

Shugart, M. S., 2008, “Comparative Electoral Systems Research. The Maturation of a Field and New Challenges Ahead", en Gallagher, M. y Mitchell, P. (eds.), The Politics of Electoral Systems, Oxford, Oxford University Press.

- - - y Carey, J., 1992, Presidents and Assemblies, Cambridge, Cambridge University Press.

Sternberger, D., 1964, Die große Wahlreform. Zeugnisse einer Bemühung [La gran reforma electoral. Testimonios de un esfuerzo], Opladen, Westdeutscher Verlag.

- - - y Vogel, B. (eds.), 1969, Die Wahl der Parlamente und anderer Staatsorgane [La elección del Parlamento y otros órganos del Estado], 2 tomos, Berlín, de Gruyter.

TaAgepera, R. y Shugart, M. S., 1989, Seats and Votes. The Effects and Determinants of Electoral Systems, New Haven-Londres, Yale University Press.

Weber, M., 1998, El político y el científico, Madrid, Alianza (e. o. 1921). -_-, 2001, Ensayos sobre metodología sociológica, Buenos Aires, Amorrortu.

Wildavsky, A., 1959, “A Methodological Critique of Duverger's Political Parties", Journal of Politics 21. 